\title{
Pituitary Antibodies in an Adolescent with Secondary Adrenal Insufficiency and Turner Syndrome
}

\author{
Allison J. Pollock ${ }^{a}$ Tasa S. Seibert ${ }^{b}$ Cristiana Salvatoric Patrizio Catureglic, $d$ \\ David B. Allen ${ }^{a}$ \\ a Department of Pediatrics, University of Wisconsin School of Medicine and Public Health, Madison, Wis., \\ ${ }^{b}$ Department of Pediatrics, Case Western Reserve University School of Medicine, Cleveland, Ohio, 'Department of \\ Pathology, Johns Hopkins University, and d Feinstone Department of Molecular Microbiology and Immunology, \\ Johns Hopkins Bloomberg School of Public Health, Baltimore, Md., USA
}

\section{Established Facts}

- Patients with Turner syndrome (TS) have an increased risk of developing autoimmune diseases (such as Hashimoto's thyroiditis, celiac disease, inflammatory bowel disease, and others).

- Pathological examination of the pituitary biopsy, an invasive and expensive surgical procedure, remains the gold standard to diagnose with certainty cases of autoimmune hypophysitis (AH).

- Demonstration of circulating pituitary antibodies expands the noninvasive diagnostic options for AH.

\section{Novel Insights}

- AH should be considered in TS patients presenting with secondary adrenal insufficiency.

\section{Key Words}

Pituitary gland · Adrenal insufficiency · Autoantibodies ·

Turner syndrome $\cdot$ Hypophysitis

\section{Abstract \\ Background/Aims: Autoimmune hypophysitis $(\mathrm{AH})$ is a rare inflammatory disease of the pituitary gland causing varying degrees of hypopituitarism and/or sellar compression. Cra- nial MRI remains the best noninvasive tool to diagnose $\mathrm{AH}$, although a diagnosis of certainty requires pituitary biopsy. The objective of this study was to assess the utility of detect-}

\section{KARGER}

(c) 2016 S. Karger AG, Basel

E-Mail karger@karger.com

www.karger.com/hrp ing pituitary antibodies for the diagnosis of AH. Methods: A 15-year-old female with Turner syndrome (TS), hypothyroidism, and ovarian failure presented acutely with hypocortisolism. Laboratory studies revealed secondary adrenal insufficiency. MRI showed a hypotrophic pituitary gland and loss of the posterior pituitary bright spot. To establish an autoimmune basis for the adrenal insufficiency, serum was analyzed by double indirect immunofluorescence for the presence of pituitary autoantibodies. Results: The patient's serum con-

P.C. and D.B.A. are co-senior authors for this article. 
tained autoantibodies that recognized $36 \%$ of the adrenocorticotropic hormone-secreting cells, suggesting that these adenohypophyseal cells were targeted by autoimmunity. The serum contained antibodies that identified the majority of the gonadotropin-secreting cells (FSH 77\%, LH 65\%). No recognition of $\mathrm{GH}-$, prolactin-, and TSH-secreting cells was found. Preabsorption experiments showed that antigenic targets of autoantibodies were not anterior pituitary hormones themselves. Conclusion: Demonstration of circulating pituitary antibodies expands the diagnostic options for AH. In this adolescent with TS, positive and cell-specific pituitary antibodies suggested that $\mathrm{AH}$ was the cause of her secondary adrenal insufficiency.

(c) 2016 S. Karger AG, Basel

\section{Introduction}

Autoimmune hypophysitis $(\mathrm{AH})$ is an inflammatory disease of the pituitary gland that typically presents with varying degrees of hypopituitarism and/or signs of sellar compression [1]. It can arise spontaneously (primary forms) [2] or be induced by identifiable agents (secondary forms), such as therapeutic administration of monoclonal antibodies that block specific immune checkpoints. Ipilimumab, in particular, is a humanized monoclonal antibody directed against the $\mathrm{T}$-cell molecule CTLA-4 $[3,4]$. Primary hypophysitis is rare, representing $0.5 \%$ of all cases of hypopituitarism with abnormal pituitary imaging [5]. Secondary hypophysitis is more common with an incidence estimated at $11 \%$ of all cancer patients treated with ipilimumab [6-8]. Both primary and secondary forms of $\mathrm{AH}$ are exceedingly rare in children [9].

Although a definitive diagnosis of $\mathrm{AH}$ still requires pathological examination of a pituitary biopsy obtained through an invasive surgical procedure [10], increased awareness of this disease in the medical community has led to more clinical diagnoses, based on the presenting symptoms, endocrine function, and, above all, pituitary MRI. Characteristic MRI findings at presentation include symmetric enlargement of the pituitary gland, thickening of the stalk, loss of the normal posterior pituitary bright spot, strong and homogenous enhancement after gadolinium, and presence of a dark signal intensity area around the pituitary and in the cavernous sinus on T2-weighted images [11, 12]. In later disease stages, MRI shows an atrophic pituitary, consistent with empty sella [13-15]. Detection of pituitary antibodies has been used to aid in the diagnosis of $\mathrm{AH}$ [16], and has recently been applied in a large cohort of patients with pituitary diseases [17]. This method, based on indirect immunofluorescence (IIF) and normal human pituitary gland substrates, can identify not only whether the patient serum contains antibodies against the pituitary gland (single IIF), but also what type of hormone-secreting cells the patient's antibodies recognize (double IIF) [17]. Published data about sensitivity and specificity of pituitary antibodies are not available. From analysis of the literature and previous laboratory experience, it appears that the pituitary antibody immunofluorescence assay has an outstanding specificity and poor sensitivity, a sensitivity that, however, greatly improves when proper methodological steps are used.

Turner syndrome (TS) caused by abnormalities (structural and/or numeric) of the $\mathrm{X}$ chromosome is associated with development of autoimmune diseases [18, 19]. The most striking association is with autoimmune thyroiditis (40-50\% of TS patients) [20,21]. Other common associations are with celiac disease, inflammatory bowel disease, vitiligo, and idiopathic thrombocytopenic purpura [22]. A 1980 case report described the presence of pituitary antibodies in a 17 -year-old TS patient with short stature and primary amenorrhea [23]. She had elevated serum gonadotropin levels (indicating normally functioning gonadotrophs) and thyroid antibodies with subclinical hypothyroidism (indicating normally functioning thyrotrophs). Double IIF testing revealed the presence of pituitary antibodies specifically recognizing the somatotrophs, suggesting that pituitary autoimmunity contributed to her GH deficiency. The same report also measured thyroid and pituitary antibodies in 16 additional TS patients, finding 10 positive for thyroid antibodies but none for pituitary antibodies [23]. A subsequent case-control study compared serum antibodies with four endocrine glands (thyroid, pituitary, adrenals, and pancreatic islets) and the stomach wall by single IIF in a cohort of 77 TS patients (age range 5-14 years) and 154 age-matched female controls. Pituitary antibodies were found in 3 of the 77 cases (4\%) and in none of the controls [24].

The goal of this study was to determine whether pituitary antibodies could be used to establish an autoimmune pathogenesis for the secondary adrenal insufficiency diagnosed in a patient with TS. The subject and her parents have given their informed assent and consent, respectively, and the case report was exempt from review by the University of Wisconsin Institutional Review Board. 


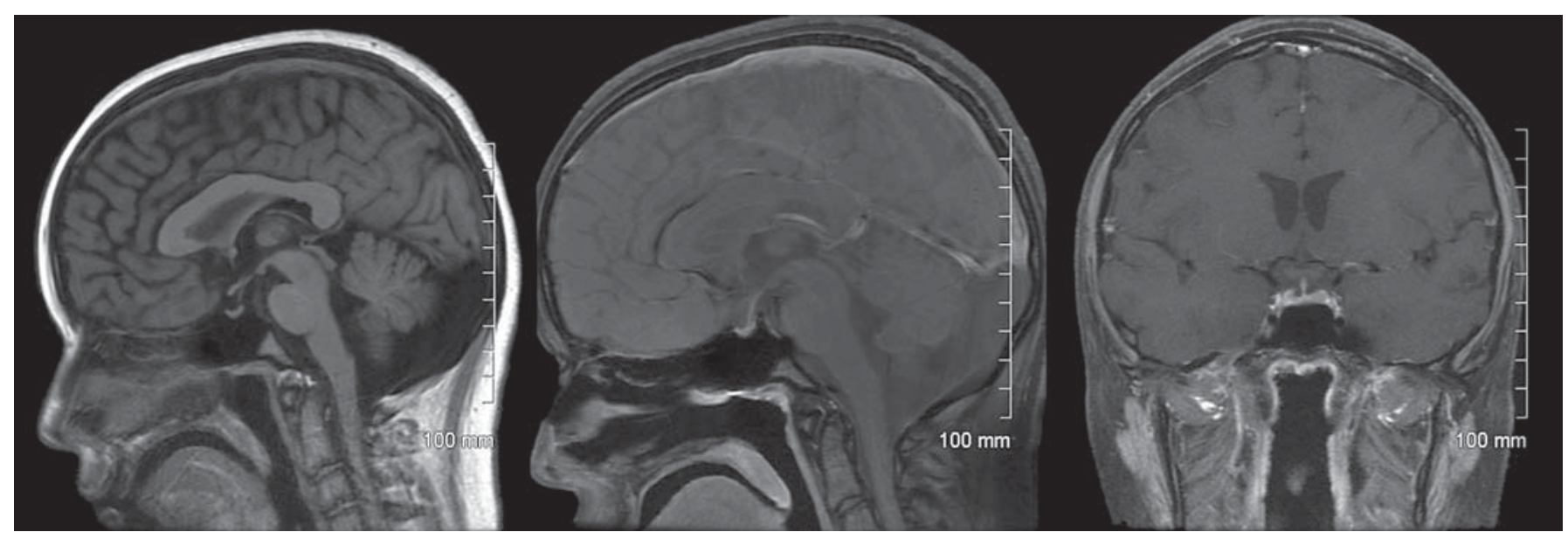

Fig. 1. Sagittal T1 MRI of the brain. The pituitary is relatively small for the patient's age, measuring less than $4 \mathrm{~mm}$ in the craniocaudal dimension. The infundibulum is present. There is no definite T1 hyperintense posterior pituitary. There is no sellar or suprasellar mass. The optic chiasm is unremarkable.

\section{Case Report}

A 15-year-old female with a known history of TS presented to an outside emergency department with altered mental status, fever, distributive shock, and respiratory failure. Laboratory and imaging studies showed hypoglycemia and right lobar pneumonia. The patient was administered intravenous antibiotics and transferred to a pediatric intensive care unit on an epinephrine drip and escalating respiratory support due to an acutely worsening condition. After obtaining blood samples for random cortisol and adrenocorticotropic hormone (ACTH), she was administered hydrocortisone for a presumptive diagnosis of adrenal insufficiency. The patient improved following glucocorticoid administration, with normalization of the low blood pressures, but polydipsia and polyuria developed, suggesting an underlying diabetes insipidus that had been masked by the glucocorticoid deficiency. She was started on desmopressin acetate and hydrocortisone. Initial laboratory results were consistent with secondary adrenal insufficiency (ACTH $<5 \mathrm{pg} / \mathrm{ml}$, cortisol $1.7 \mu \mathrm{g} / \mathrm{dl}$ ) and partial diabetes insipidus ( $\mathrm{Na} 146$ $\mathrm{mmol} / \mathrm{l}$, serum osmolality $294 \mathrm{mOsm} / \mathrm{kg}$, urine osmolality 427 $\mathrm{mOsm} / \mathrm{kg})$. Prolactin was normal $(6.6 \mathrm{ng} / \mathrm{ml})$ and IGF-1 was borderline low (150 ng/ml, reference range 147-646). Further history revealed an episode of hypoglycemia 2 months prior to presentation during a routine tonsillectomy.

In addition to TS, her past medical history was notable for bicuspid aortic valve, coarctation of the aorta status after repair, and horseshoe kidney. Her height had remained stable throughout her childhood, around the 10th-15th percentile for her age without GH therapy. Two years prior to admission, she was diagnosed with primary hypothyroidism (TSH $8.43 \mathrm{mIU} / \mathrm{ml}$, free T4 $0.77 \mathrm{ng} / \mathrm{dl}$ ), presumably of autoimmune origin (thyroid antibodies were not obtained), and was replaced with levothyroxine. Analysis of the gonadal axis at the age of 12 years had shown hypergonadotropic hypogonadism (LH $28.3 \mathrm{mIU} / \mathrm{ml}$, FSH $122.2 \mathrm{mIU} / \mathrm{ml}$, and estradiol $<5 \mathrm{pg} / \mathrm{ml}$ ) in context of delayed puberty, which had prompted initiation of estrogen replacement.

Autoimmune Hypophysitis in Turner Syndrome
Cranial MRI revealed a pituitary gland of smaller size $(4 \mathrm{~mm}$ in height) than the reference population and loss of the physiologic posterior pituitary bright spot (fig. 1). The patient remained in the intensive care unit for the first 9 days of hospitalization. Her clinical course was complicated by aspiration pneumonia, diarrhea, electrolyte and metabolic abnormalities (hypokalemia, hypophosphatemia, hypomagnesemia, and hypocalcemia), hypertension, microhematuria, proteinuria, anemia, and thrombocytopenia. She was discharged on hospital day 15 , with a much improved energy level, normalized electrolytes, glucoses, blood pressure, and mental status. Hormone replacement prescribed at discharge included cortisol, thyroid hormone, antidiuretic hormone, and estrogen. Proteinuria, anemia, and thrombocytopenia resolved within 1 month of discharge.

\section{Materials and Methods}

\section{Single and Double IIF}

IIF was performed using a human pituitary gland collected at autopsy, as has recently been described [17]. Briefly, the gland was snapped frozen in liquid nitrogen, embedded in OCT compound (Sakura Finetek, Torrance, Calif., USA), and then cut at the cryostat (Leica CM-1950; Bannockburn, Ill., USA) into 5- $\mu \mathrm{m}$ sections. Sections were fixed in ice-cold acetone, air-dried, blocked with a commercial serum-free reagent (DAKO, catalog X0909; Carpinteria, Calif., USA), and then used for the experiments. For single IIF staining, sections were incubated for $1 \mathrm{~h}$ at room temperature with the patient serum (diluted 1:10 in phosphate-buffered saline, supplemented with $0.2 \%$ Tween-20). Following washes in phosphatebuffered saline, sections were incubated for $1 \mathrm{~h}$ at room temperature with a secondary antibody conjugated to a green (FITC) fluorochrome directed against human immunoglobulins $G$ [goat antihuman $\mathrm{F}(\mathrm{ab})_{2}$; Jackson Immunoresearch Laboratories, diluted 1:400]. After another wash, sections were counterstained with DAPI (Roche, Indianapolis, Ind., USA) to identify the nuclei, and Sudan Black to decrease the background autofluorescence [25]. 

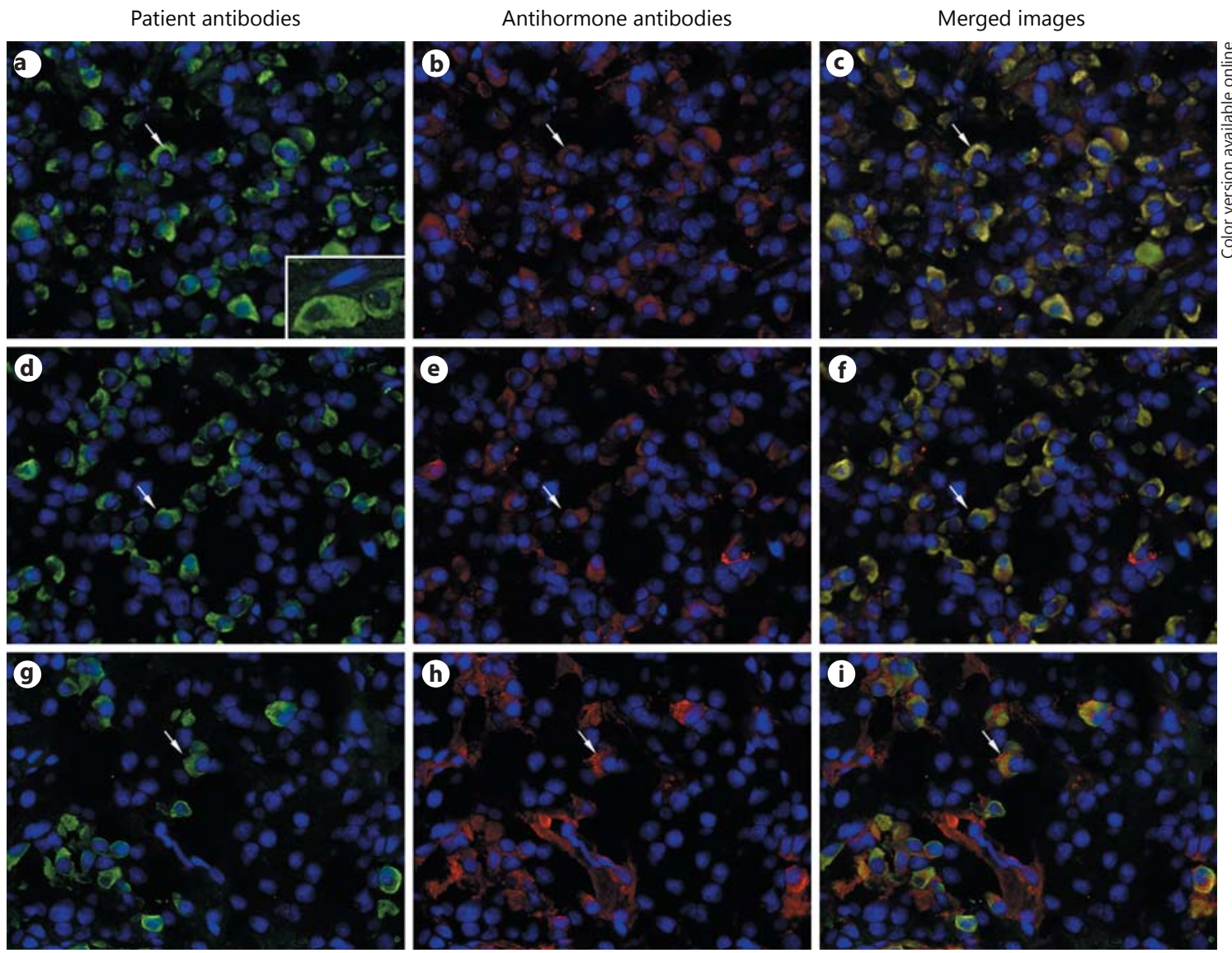

Fig. 2. Double IIF staining using patient serum and commercial antihormone antibodies. The left panels $(\mathbf{a}, \mathbf{d}, \mathbf{g})$ show the binding of the anterior pituitary cells by the patient antibodies, detected using a secondary antibody conjugated with a green fluorochrome. The middle panels show the staining of the anterior pituitary cells

Sections were then mounted with $80 \%$ glycerol and analyzed using an AxioImager A2 fluorescence microscope (Carl Zeiss, Thornwood, N.Y., USA) equipped with a digital camera.

To identify the hormone-producing cells targeted by the patient's antibodies (double IIF staining), a commercial rabbit polyclonal antihormone antibody was added together with the patient's serum during the primary incubation, followed by an antirabbit immunoglobulin antibody conjugated to a red (Dylight 649) fluorochrome during the secondary incubation. The antihormone antibodies, purchased from the National Hormone and Peptide Program (Torrance, Calif., USA), were directed against GH, prolactin, ACTH, LH $\beta$ subunit, FSH $\beta$ subunit, and TSH $\beta$ subunit.

\section{Preabsorption of Patient Serum with Native FSH $\beta$ Antigen}

To determine whether the patient antibodies directed against FSH-secreting cells recognized FSH itself or instead other antigens expressed by these cells, we incubated the patient serum overnight at $4{ }^{\circ} \mathrm{C}$ with $100 \mu \mathrm{g} / \mathrm{ml}$ of native $\mathrm{FSH} \beta$. As control, we incubated the commercial anti-FSH $\beta$ antibody with native $\mathrm{FSH} \beta$ antigen $(100 \mu \mathrm{g} / \mathrm{ml})$ under the same conditions (overnight at $4^{\circ} \mathrm{C}$ ). using commercial anti-FSH $\beta$ (b), anti-LH $\beta$ (e), or anti-ACTH (h) antibodies, detected by a secondary antibody conjugated with a red fluorochrome. The right panels $(\mathbf{c}, \mathbf{f}, \mathbf{i})$ show the merging of the previous two panels. Cells that are recognized by both commercial and patient antibodies appear in yellow.

Cell Counting and Expression of the Results

To quantify the percentage of hormone-secreting cells recognized by the patient's antibodies, we first counted the total number of pituitary acinar cells in five $20 \times$ microscope fields using the DAPI nuclear stain. We then counted the number of cells secreting each of the six anterior pituitary hormones, and then how many of them were recognized by the patient's antibodies.

\section{Results}

The patient's serum contained antibodies that recognized a large number of anterior pituitary cells (fig. 2, left panels). This recognition highlighted the cytosol as fine granules that imparted a reticular pattern (fig. $2 \mathrm{a}$, inset). Double IIF showed that the pituitary cells targeted by the patient's antibodies were FSH-secreting (fig. 2, top row), 
Fig. 3. Preabsorption of the patient serum (a) and the commercial anti-FSH $\beta$ antibody (b) with the commercial human FSH $\beta$ antigen. The preabsorption does not affect the pituitary cell recognition by the patient serum, but it almost completely abolishes the recognition by the commercial antibody.
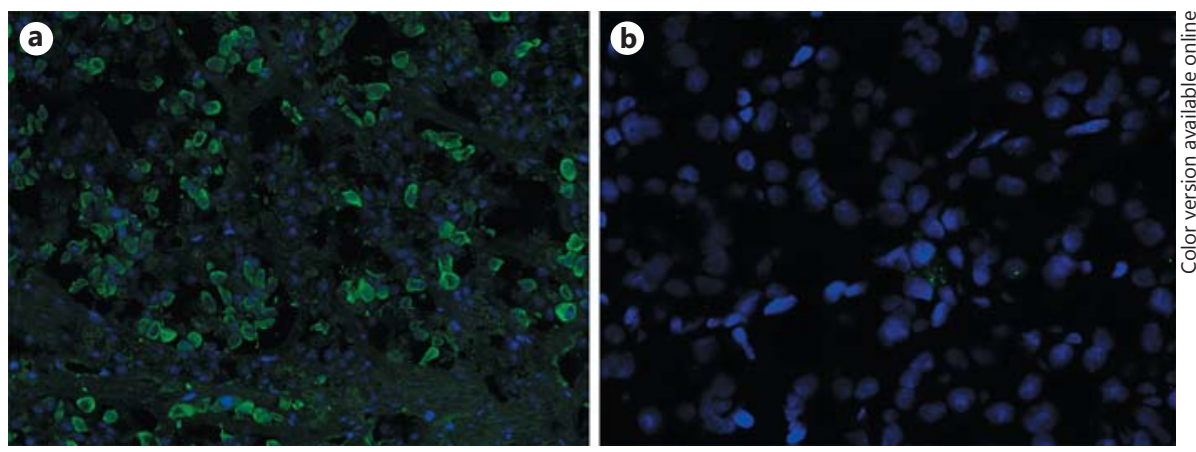

Table 1. Recognition and cell-specificity of anterior pituitary cells by the patient's serum

\begin{tabular}{|c|c|c|c|c|c|c|c|c|c|c|c|c|c|c|}
\hline & $\begin{array}{l}\text { Overall } \\
\text { anterior } \\
\text { pituitary } \\
\text { cells, } \mathrm{n}\end{array}$ & $\begin{array}{l}\text { Overall } \\
\text { endocrine } \\
\text { cells, n }\end{array}$ & \multicolumn{2}{|c|}{ GH cells } & \multicolumn{2}{|c|}{ PRL cells } & \multicolumn{2}{|c|}{ TSH cells } & \multicolumn{2}{|c|}{ ACTH cells } & \multicolumn{2}{|c|}{ LH cells } & \multicolumn{2}{|c|}{ FSH cells } \\
\hline Field 1 & 456 & 362 & 66 & 0 & 40 & 0 & 7 & 0 & 12 & $6(50)$ & 28 & $26(93)$ & 46 & $33(72)$ \\
\hline Field 2 & 490 & 351 & 51 & 0 & 48 & 0 & 14 & 0 & 11 & $5(45)$ & 33 & $17(52)$ & 32 & $29(91)$ \\
\hline Field 3 & 484 & 377 & 67 & 0 & 44 & 0 & 9 & 0 & 17 & $4(24)$ & 25 & $13(52)$ & 30 & $27(90)$ \\
\hline Average & 461 & 346 & 59 & 0 & 41 & 0 & 11 & 0 & 14 & $5(36)$ & 31 & $20(65)$ & 39 & $30(77)$ \\
\hline
\end{tabular}

Numbers are based on observations of $\times 20$ microscopic fields. The term 'overall anterior pituitary cells' refers to the DAPI-positive cells that both localize inside the acini (thus mostly representing endocrine cells) and along the connective tissue framework. 'Overall endocrine cells' indicate the number of acinar cells.

LH-secreting (fig. 2, middle row), or ACTH-secreting (fig. 2, bottom row). In particular, the antibodies recognized the majority of the gonadotrophs ( $77 \%$ of the FSHsecreting and $65 \%$ of the LH-secreting cells) and about a third (36\%) of the corticotrophs (table 1). No recognition of GH-, prolactin-, or TSH-secreting cells was found (table 1).

\section{The Antigenic Targets Are Not the Hormones Themselves}

Merging of the images obtained using the antihormone antibodies (left panels in fig. 2) and patient antibodies (middle panels in fig. 2) often showed that, although localized in the same cell, the two antibody types stained distinct subcellular components. For example, corticotrophs displayed a coarse granular appearance with the anti-ACTH reagent (fig. $2 \mathrm{~h}$, arrow) and a reticular appearance with the patient's antibodies (fig. $2 \mathrm{~g}$ ). These two stainings, although confined to the same cell, retained their individuality upon merging of the images

Autoimmune Hypophysitis in Turner Syndrome (fig. 2i, arrow). Preabsorption experiments provided further support to this observation. Using FSH $\beta$ as an example, we showed that the patient's serum retained its recognition pattern even after it had been saturated with commercial FSH $\beta$ antigen; thus, indicating that the target of the patient's antibodies was not the hormone itself (fig. 3a). The control experiment showed that the commercial anti-FSH $\beta$ antibody lost its ability of recognizing FSH-secreting cells after having been preabsorbed with the human FSH $\beta$ antigen (fig. 3b).

\section{Discussion}

The risk of autoimmune diseases in patients with TS is about 2-3 times higher than in the general population and increases with age $[26,27]$. While Hashimoto's thyroiditis (50\% prevalence in TS) is one of the most common autoimmune conditions associated with TS, and inflammatory bowel disease, type 1 diabetes, celiac disease, 
juvenile idiopathic arthritis, Addison's disease, psoriasis, vitiligo, and alopecia areata are also prevalent $[19,26]$. Proposed mechanisms of autoimmunity involve haploinsufficiency of $\mathrm{X}$ chromosome genes, leading to a decreased ability of the thymus to delete autoreactive $\mathrm{T}$ cells [21].

Despite this propensity for autoimmunity, hypophysitis has been reported only in one other published case that presented with GH deficiency [23]. Ascertainment bias may contribute to the low prevalence of hypophysitis in TS, since hormonal deficits of AH can be masked by replacement therapies, and the definitive diagnosis traditionally requires pituitary biopsy. Clinical and laboratory findings of the case described here are consistent with the most typical initial presentation of $\mathrm{AH}$, which is secondary adrenal insufficiency. In addition, other more common causes of AH were excluded (e.g. iatrogenic, mass of the CNS). Antipituitary antibodies were detected and recognized proportions of both corticotroph (36\%) and gonadotroph (FSH 77\% and LH 65\%) cells, reinforcing the high clinical suspicion for the diagnosis of $\mathrm{AH}$ as etiology of the patient's secondary adrenal insufficiency. While the antibodies do not replace the definitive hypophysitis diagnosis by biopsy, they strengthen the credibility of the diagnosis by adding one piece of objective laboratory evidence for pituitary autoimmunity that is not provided by clinical history, routine blood tests, and MRI.

This case illustrates that clinical suspicion for $\mathrm{AH}$ in TS patients can be obscured by clinical findings masked by preexisting hormone replacement and the definitive diagnosis impeded by practical challenges and risks of the diagnostic gold standard brain biopsy. Appropriate hormone replacement therapies - levothyroxine for primary hypothyroidism and estrogen/progesterone via oral contraceptive for primary ovarian failure in the case described - would obscure clinical clues in the setting of newly acquired complete or partial hypopituitarism. While not the case for this patient, in most girls with TS empirically treated with GH for short stature, clinical in- dicators of evolving $\mathrm{GH}$ deficiency could also be masked. Consequently, the evaluation of secondary adrenal insufficiency in a patient with TS should include functional assessment of all pituitary hormones, not only ACTH, as well as consideration of possible $\mathrm{AH}$ as the underlying etiology. This case report illustrates that detection of pituitary antibodies contributes to establishing a diagnosis of AH without the need of a pituitary biopsy, especially in patients such as this one, who do not have a sellar mass (the most common MRI finding) but rather an empty sella (indicative of long-standing pituitary pathology leading to atrophy of the gland).

In summary, using novel techniques for detecting and identifying the cytosolic staining pattern of APA, we were able to confirm the clinical suspicion for $\mathrm{AH}$ as the cause of secondary adrenal insufficiency with laboratory evidence of pituitary autoimmunity in an adolescent with TS. Individuals with TS are at increased risk for autoimmune diseases including thyroiditis, celiac disease, inflammatory bowel disease, and others. Given this proclivity toward autoimmunity, AH should be considered in TS patients presenting with secondary adrenal insufficiency. Treatment with GH, estrogen/progesterone, and thyroid hormone is common in patients with TS, so that signs and symptoms of $\mathrm{AH}$ affecting somatotropes, gonadotropes, and/or thyrotropes may be masked by pre-existing hormone replacement. When there is high clinical suspicion, identifying and classifying cytosolic staining patterns of pituitary antibodies as described in this case can be useful for supporting the diagnosis of $\mathrm{AH}$, since the definitive diagnosis with brain biopsy is invasive and often impractical.

\section{Acknowledgements}

Funding for this project was provided by NIH Postdoctoral Fellowship Grant T32 DK077586-06A1. The work was supported by patient donations to the Johns Hopkins Hypophysitis Research Center.

References

1 Leporati P, Landek-Salgado MA, Lupi I, Chiovato L, Caturegli P: IgG4-related hypophysitis: a new addition to the hypophysitis spectrum. J Clin Endocrinol Metab 2011;96:19711980.

-2 Caturegli P, Newschaffer C, Olivi A, Pomper MG, Burger PC, Rose NR: Autoimmune hypophysitis. Endocr Rev 2005;26:599-614.
- 3 Gutenberg A, Landek-Salgado MA, Tzou SC, Lupi I, Geis A, Kimura H, Caturegli P: Autoimmune hypophysitis: expanding the differential diagnosis to CTLA-4 blockade. Expert Rev Endocrinol Metab 2009;4:681-698.

-4 Bertrand A, Kostine M, Barnetche T, Truchetet ME, Schaeverbeke T: Immune related adverse events associated with anti-CTLA-4 antibodies: systematic review and meta-analysis. BMC Med 2015;13:211. 
5 Wilson V, Mallipedhi A, Stephens JW, Redfern RM, Price DE: The causes of hypopituitarism in the absence of abnormal pituitary imaging. QJM 2014;107:21-24.

6 Albarel F, Gaudy C, Castinetti F, Carre T, Morange I, Conte-Devolx B, Grob JJ, Brue T: Long-term follow-up of ipilimumab-induced hypophysitis, a common adverse event of the anti-CTLA-4 antibody in melanoma. Eur J Endocrinol 2015;172:195-204.

7 Faje AT, Sullivan R, Lawrence D, Tritos NA, Fadden R, Klibanski A, Nachtigall L: Ipilimumab-induced hypophysitis: a detailed longitudinal analysis in a large cohort of patients with metastatic melanoma. J Clin Endocrinol Metab 2014;99:4078-4085.

8 Min L, Hodi FS, Giobbie-Hurder A, Ott PA, Luke JJ, Donahue H, Davis M, Carroll RS, Kaiser UB: Systemic high-dose corticosteroid treatment does not improve the outcome of ipilimumab-related hypophysitis: a retrospective cohort study. Clin Cancer Res 2015; 21:749-755.

-9 Gellner V, Kurschel S, Scarpatetti M, Mokry M: Lymphocytic hypophysitis in the pediatric population. Childs Nerv Syst 2008;24:785792.

10 Howlett TA, Levy MJ, Robertson IJ: How reliably can autoimmune hypophysitis be diagnosed without pituitary biopsy. Clin Endocrinol (Oxf) 2010;73:18-21.

-11 Gutenberg A, Larsen J, Lupi I, Rohde V, Caturegli P: A radiologic score to distinguish autoimmune hypophysitis from nonsecreting pituitary adenoma preoperatively. AJNR Am J Neuroradiol 2009;30:1-8.
12 Nakata Y, Sato N, Masumoto T, Mori H, Akai $\mathrm{H}$, Nobusawa $\mathrm{H}$, Adachi $\mathrm{Y}$, Oba $\mathrm{H}$, Ohtomo $\mathrm{K}$ : Parasellar T2 dark sign on MR imaging in patients with lymphocytic hypophysitis. AJNR Am J Neuroradiol 2010;31:1944-1950.

13 Gao H, Gu YY, Qiu MC: Autoimmune hypophysitis may eventually become empty sella. Neuro Endocrinol Lett 2013;34:102-106.

14 Karaca Z, Tanriverdi F, Unluhizarci K, Kelestimur F, Donmez H: Empty sella may be the final outcome in lymphocytic hypophysitis. Endocr Res 2009;34:10-17.

15 Lupi I, Zhang J, Gutenberg A, Landek-Salgado M, Tzou SC, Mori S, Caturegli P: From pituitary expansion to empty sella: disease progression in a mouse model of autoimmune hypophysitis. Endocrinology 2011;152:41904198.

16 De Bellis A, Bellastella G, Colella C, Bizzarro A, Bellastella A, Esposito K: Use of serum pituitary antibodies to improve the diagnosis of hypophysitis. Expert Rev Endocrinol Metabol 2014;9:465-476.

17 Ricciuti A, De Remigis A, Landek-Salgado MA, De Vincentiis L, Guaraldi F, Lupi I, Iwama S, Wand GS, Salvatori R, Caturegli P: Detection of pituitary antibodies by immunofluorescence: approach and results in patients with pituitary diseases. J Clin Endocrinol Metab 2014;99:1758-1766.

-18 Bakalov VK, Gutin L, Cheng CM, Zhou J, Sheth P, Shah K, Arepalli S, Vanderhoof V, Nelson LM, Bondy CA: Autoimmune disorders in women with Turner syndrome and women with karyotypically normal primary ovarian insufficiency. J Autoimmun 2012;38: 315-321.

19 Lleo A, Moroni L, Caliari L, Invernizzi P: Autoimmunity and Turner's syndrome. Autoimmun Rev 2012;11:A538-A543.
20 Germain EL, Plotnick LP: Age-related antithyroid antibodies and thyroid abnormalities in Turner syndrome. Acta Paediatr Scand 1986;75:750-755.

21 Grossi A, Crino A, Luciano R, Lombardo A, Cappa M, Fierabracci A: Endocrine autoimmunity in Turner syndrome. Ital J Pediatr 2013;39:79.

22 Bianchi I, Lleo A, Gershwin ME, Invernizzi P: The $\mathrm{X}$ chromosome and immune associated genes. J Autoimmun 2012;38:J187-J192.

23 Bottazzo GF, McIntosh C, Stanford W, Preece M: Growth hormone cell antibodies and partial growth hormone deficiency in a girl with Turner's syndrome. Clin Endocrinol (Oxf) 1980;12:1-9.

24 Gluck M, Attanasio A, Speer U, Butenandt O, Tietze HU, Scherbaum WA: Prevalence of autoantibodies to endocrine organs in girls with Ullrich-Turner syndrome aged 5-14 years. Horm Res 1992;38:114-119.

-25 Romijn HJ, van Uum JF, Breedijk I, Emmering J, Radu I, Pool CW: Double immunolabeling of neuropeptides in the human hypothalamus as analyzed by confocal laser scanning fluorescence microscopy. J Histochem Cytochem 1999;47:229-236.

26 Jorgensen KT, Rostgaard K, Bache I, Biggar RJ, Nielsen NM, Tommerup N, Frisch M: Autoimmune diseases in women with Turner's syndrome. Arthritis Rheum 2010;62:658666.

27 Mortensen KH, Cleemann L, Hjerrild BE, Nexo E, Locht $\mathrm{H}$, Jeppesen EM, Gravholt $\mathrm{CH}$ : Increased prevalence of autoimmunity in Turner syndrome - influence of age. Clin Exp Immunol 2009;156:205-210. 